\title{
Determination of Crystalline Content Gradients in Cold-Drawn Poly-L-Lactic Acid Films by DSC
}

\author{
Anne O'Connor \\ Cleveland State University, a.oconnor@csuohio.edu
}

A. Riga

Cleveland State University

John F. Turner II

Cleveland State University, J.F.TURNER@csuohio.edu

Follow this and additional works at: https://engagedscholarship.csuohio.edu/scichem_facpub

Part of the Chemistry Commons

How does access to this work benefit you? Let us know!

Publisher's Statement

The final publication is available at Springer via http://dx.doi.org/10.1023/

B:JTAN.0000028025.93248.48

\section{Recommended Citation}

O'Connor, Anne; Riga, A.; and Turner, John F. II, "Determination of Crystalline Content Gradients in ColdDrawn Poly-L-Lactic Acid Films by DSC" (2004). Chemistry Faculty Publications. 307.

https://engagedscholarship.csuohio.edu/scichem_facpub/307

This Article is brought to you for free and open access by the Chemistry Department at EngagedScholarship@CSU. It has been accepted for inclusion in Chemistry Faculty Publications by an authorized administrator of EngagedScholarship@CSU. For more information, please contact library.es@csuohio.edu. 


\title{
DETERMINATION OF CRYSTALLINE CONTENT GRADIENTS IN COLD-DRAWN POLY-L-LACTIC ACID FILMS BY DSC
}

\author{
A. O'Connor, A. Riga and J. F. Turner II
}

\begin{abstract}
Poly $L$ lactic acid (PLLA) is a semi crystalline, optically active, biodegradable, and biocompatible polymer that has been utilized extensively in biomedical applications as an implantable artificial cell scaffold material. In its crystalline form, PLLA is piezoelectric and it has been implicated in the enhancement of electromechanically induced osteogenesis in vivo. In its amorphous state, however, PLLA does not exhibit piezoelectricity. By uniaxially cold drawing the polymer, PLLA can be endowed with varying degrees of piezoelectricity. It is important to understand the crystalline architecture of drawn PLLA so that the osteogenic potential imparted by piezoelectricity, if any, can be differentiated from the effects of sample crystallinity. In our work we investigate the induced crystallinity for samples of drawn PLLA at draw ratios between 1.0 and 5.5 by differential scanning calorimetry (DSC). As long range molecular ordering occurs along the draw axis, we observe an increase in the average percent crystallinity up to a draw ratio of 5.0 and a slight decrease at a draw ratio of 5.5. More importantly, we observe significant heterogeneity in the crystalline content along the draw axis of standard dumbbells cut from PLLA and cold drawn to representative draw ratios of 2.5 and 4.0. On average, the highest percent crystallinity occurs nearest the dumbbell center, but the maximum crystallinity is independent of draw ratio. Therefore, the draw ratio should not be considered a semi quantitative estimate of localized PLLA crystallinity and point to point analysis of crystallinity in PLLA samples is required for constructing scaffolds with enhanced cell growth properties.
\end{abstract}

Keywords: crystallinity, DSC, osteogenesis, PLLA, scaffold, XRD

\section{Introduction}

The most utilized of the commercially available biodegradable and biocompatible polymers are poly-( $\alpha$-hydroxy acids), poly-(lactide) and poly-(glycolides). These polymers are employed as suture materials, tissue scaffolds and supports, drug delivery devices, and have more recently been used to construct three-dimensional architectures for cell seeding in biomedical applications [1-4]. Poly- $L$-lactide is an optically active semi-crystalline form of poly-(lactide) and has the general formula poly- $\left(\mathrm{O}-\mathrm{CO}-\mathrm{CH}\left(\mathrm{CH}_{3}\right)\right)_{\mathrm{n}}$. PLLA has been used as an artificial scaffold for retinal pigment epithelium studies as well as other tissue regeneration studies, employed as a 
bone implant material in animals as well as humans, and more recently has been considered a good candidate for the construction of internal fixation devices [5-10]. It is the biodegradability and mechanical stability of PLLA that make it an appealing alternative to metal and ceramic implants that require surgical removal [11, 12].

In vivo, PLLA is degraded by hydrolytic de-esterification into lactic acid with the non-toxic lactic acid monomers being further metabolized in the carboxylic acid cycle where they are expelled by the lungs as carbon dioxide and water [13-15]. The biodegradation rate of PLLA is strongly influenced by its morphology and crystallinity. By controlling these sample parameters it is possible to tailor the mechanical properties of the polymer to suit a particular application [16-19]. For example, molecular orientation is increased when PLLA is cold-drawn at temperatures below its melting temperature $\left(T_{\mathrm{m}}\right)$, but above its glass-transition temperature $\left(T_{\mathrm{g}}\right)[20,21]$. In addition, the isotactic sequences comprising optically active PLLA allow it to readily crystallize from solution [1].

In our investigation, the percent crystallinity of PLLA is studied as a function of draw ratio and position along the draw axis using DSC. Although homogeneous sample crystallinity and long-range molecular ordering are sought-after characteristics, uniformly controlling these parameters in PLLA is complicated by the initial microstructure of the polymer and the bulk mechanical properties that ensue. During colddrawing, unoriented PLLA first becomes thinner at one point along the draw axis in a process known as necking down. The necking down mechanism is observed in other semi-crystalline polymers and correlates to the unfolding of molecular chains during the drawing process [22]. As drawing is continued, the neck grows in length as regions of the sample lying just outside the necking down region become incorporated into a short transition region called the necking zone. The necking zone continues to migrate during cold-drawing at the expense of the adjacent undrawn regions [20]. The objective of our work is to investigate the extent to which draw ratio can be used as an indicator of percent crystallinity in PLLA. This work is the first step in the investigation of the potentially separate roles of piezoelectricity and crystallinity in the osteogenic potential of PLLA.

In our work, PLLA draw ratios between 1.0 and 5.5 are investigated. The draw ratio, $D$, is defined as:

$$
D=\frac{l_{\mathrm{f}}}{l_{\mathrm{i}}}
$$

where $l_{\mathrm{i}}$ is the initial sample length and $l_{\mathrm{f}}$ is the final sample length.

This range of draw ratios was selected based on earlier investigations of PLLA piezoelectricity, which has been implicated as a contributor to its osteogenic properties [23]. The reported piezoelectric constant of PLLA increases with drawing up to a draw ratio of 5.0 and is attributed to shearing along the asymmetric carbons present in the repeating units of neighboring chains [23-26]. At greater draw ratios, the piezoelectricity of PLLA diminishes [23]. Although several models describing the molecular chain unfolding mechanics during drawing have been reported, the precise 
method of unfolding and chain elongation remains unclear [27, 28]. Moreover, the behavior of crystallites likely differs during the drawing process from the behavior of more randomly ordered regions. It is also important to make a distinction between long-range chain orientation, which yields shear piezoelectricity in PLLA, and crystalline order, repeating units of three dimensional molecular geometry. While the cold-drawing process can enhance the crystalline content of PLLA, as our results show, it is primarily a tool for endowing a sample with orientational chain order.

\section{Experimental}

\section{Preparation of polymer plaques}

Poly-L-lactide pellets (Birmingham Polymers, Birmingham, AL) having a mass average molecular mass, $M_{\mathrm{m}}$, equal to 134000 and a number average molecular mass, $M_{\mathrm{n}}$, equal to 83900 were utilized for this work. The inherent viscosity, [ $\eta$ ], of the PLLA pellets is $0.95 \mathrm{dL} \mathrm{g}^{1}$ in $\mathrm{CHCl}_{3}$ at $30^{\circ} \mathrm{C}$. The pellets are first compression molded into plaques using a 12-ton manual hydraulic press (Carver) equipped with temperature controllers (Omega) to maintain the temperature of the platens at $195^{\circ} \mathrm{C}$. The PLLA pellets are then placed between Teflon coated foils in a $15.2 \mathrm{~cm}$ square frame having a thickness of $0.75 \mathrm{~mm}$. The frame is placed between the heated platens for two minutes prior to the application of pressure. The PLLA is then molded for 5 min under a pressure of $187.3 \mathrm{~N} \mathrm{~cm}^{2}$. After molding, the plaques are immediately quench-cooled in dry ice to prevent further crystallization. The molded plaques are cut into standard dumbbell shapes measuring $6.35 \mathrm{~cm}$ long by $1.27 \mathrm{~cm}$ wide at the ends, with the narrowest part in the middle being $0.25 \mathrm{~cm}$ using a standard die (ASTM Type V, Dewes-Gumbs Die Company). All samples are stored in a desiccator at $0^{\circ} \mathrm{C}$.

\section{Cold-drawing of PLLA}

A mechanical stretcher was constructed from a stepper motor (AMP, Size 23, 4023-819) and custom threaded rod (worm) assembly. An aluminum rod attached to a movable chuck on the worm passes through the insulated wall of a conventional laboratory oven (Cole Parmer 05015-58) and terminates in an adjustable clamp. One end of the polymer is clamped to the rod assembly and the other end is clamped to a fixed platform inside the oven. The stepper motor driver circuit is interfaced to the parallel port of a computer (Gateway, Pentium 4) using control software written in MFC/C++ (Microsoft Visual Studio 6.0). The software enables user control of the draw ratio and draw rate. A draw rate of $\sim 0.1 \mathrm{~cm} \mathrm{~s}^{1}$ was employed for the PLLA samples described here. During the drawing process, the temperature is held at $(66 \pm 1)^{\circ} \mathrm{C}$. Higher temperatures cause the sample to become brittle and lead to frequent breakage of the sample before stretching is completed. The temperature was monitored using a multimeter (Fluke, 79III) and thermocouple (Fluke, 80TK). Three sets of samples were prepared with draw ratios of 1.0, 1.5, 2.0, 2.5, 3.0, 3.5, 4.0, 4.5, 5.0 and 5.5 as shown in Fig. 1a. In addition, six samples with a draw ratio of 2.5 and 4.0 were prepared. 

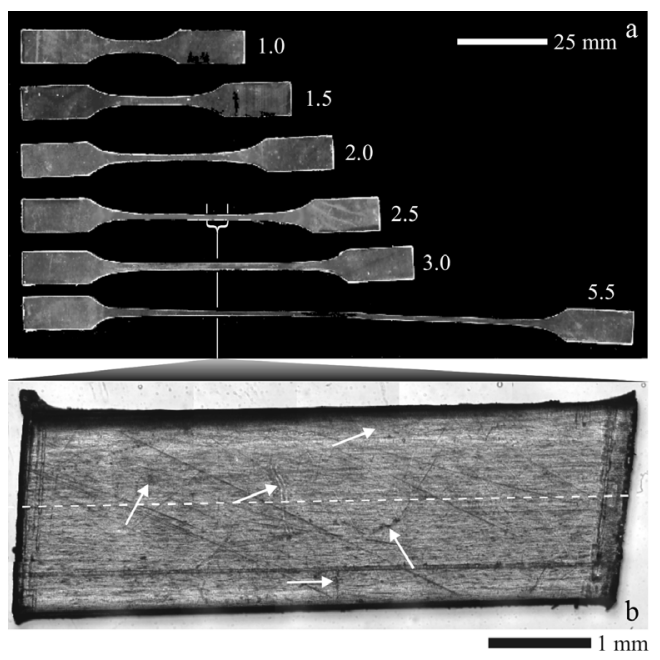

Fig. 1 a Compression molded undrawn and drawn PLLA dumbbells. Draw ratios are $1.0,1.5,2.0,2.5,3.0,3.5,4.0,4.5,5.0$ and 5.5. $\mathrm{b}$ Image of PLLA with draw ratio 2.5 , segment 0 . The arrows indicate unoriented regions and the dotted line corresponds to the draw axis

\section{X-ray diffraction}

X-ray diffraction (Phillips, Xpress) is performed on representative PLLA samples of draw ratio 1.0 and 4.0 in order to determine the extent of crystallinity in the undrawn and highly drawn samples. Sections from the PLLA samples are cut to size and arranged in the sample aperture with their draw axes parallel to each other. Perpendicular and parallel diffraction spectra are obtained for the drawn sample.

\section{Scanning electron microscopy (SEM)}

PLLA of draw ratios 1.0, 2.5 and 4.0 were examined by SEM (Jeol, model JSM-5900LV) to determine the changes in surface morphology related to the cold-drawing process. The images were acquired under low vacuum at $500 \times$ magnification with a $15 \mathrm{kV}$ acceleration voltage in order to assess the long-range morphology in bare samples of drawn PLLA.

\section{Differential scanning calorimetry}

The thermal properties of the undrawn and drawn PLLA were measured with a differential scanning calorimeter (TAI, model MTDSC 2920) calibrated with Indium, which melts at $156.7^{\circ} \mathrm{C}$ and has a heat of fusion equal to $28.4 \mathrm{~J} \mathrm{~g}^{1}$ [29]. Pieces of drawn and undrawn PLLA samples weighing approximately $4 \mathrm{mg}$ were cut from the respective dumbbell centers using a dry razor blade that had been heated to $65^{\circ} \mathrm{C}$ in a water bath to minimize cutting artifacts. Samples having draw ratios from 1.0 to 5.5 were investigated using conventional DSC in a nitrogen atmosphere. The tempera- 
ture program heated at a rate of $5^{\circ} \mathrm{C} \mathrm{min}{ }^{1}$ from 0 to $200^{\circ} \mathrm{C}$. The glass transition temperature, $T_{\mathrm{g}}$, cold crystallization temperature, $T_{\mathrm{c}}$, melting temperature, $T_{\mathrm{m}}$, enthalpy of fusion, $\Delta H_{\mathrm{f}}$, and the enthalpy of crystallization, $\Delta H_{\mathrm{c}}$, were determined for each sample from the thermal curves using TA Universal Analysis software. The percent crystallinity is determined from the measured values of the crystallization enthalpies $\left(\Delta H_{\mathrm{c}}\right)$ and melting enthalpies $\left(\Delta H_{\mathrm{f}}\right)$ as described in the results section. Six samples of draw ratio 2.5 were cut into 9 segments, each weighing approximately $2 \mathrm{mg}$. Each segment is assigned a number based on its proximity to the dumbbell center segment, which is designated as segment 0 (Fig. 2). The samples of draw ratio 4.0 were cut into 17 segments using a similar method for assigning the segment number. All of the segments were investigated using conventional DSC at a heating rate of $5^{\circ} \mathrm{C} \mathrm{min}{ }^{1}$ in a nitrogen atmosphere. One sample of draw ratio 2.5 was run using MTDSC at a heating rate of $5^{\circ} \mathrm{C} \mathrm{min}{ }^{1}$ for comparison. The heterogeneity of the drawn dumbbells is examined by determining the combined variability in the percent crystallinity values recorded for each of its segments.

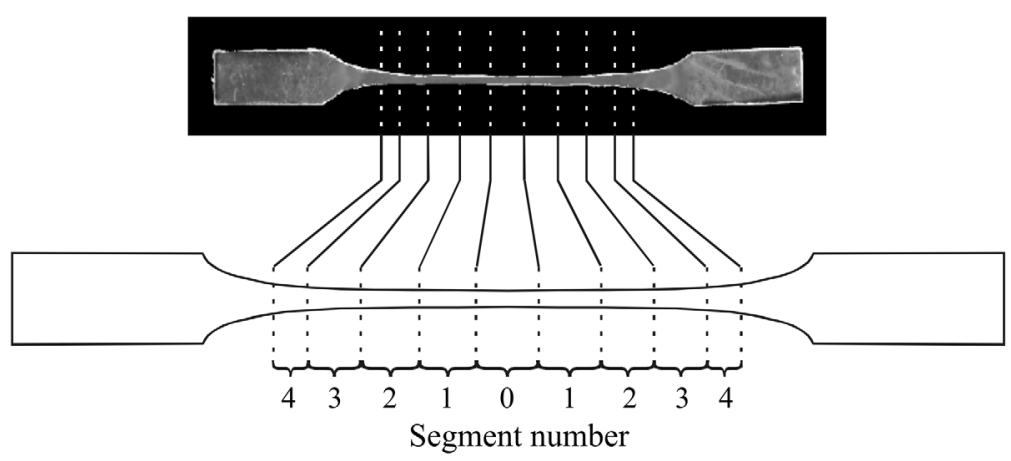

Fig. 2 Assignment of segment number for a dumbbell having a draw ratio of 2.5. The segment length decreases further from the central region so that each segment has approximately the same mass

\section{Standard optical microscopy}

White light images of the PLLA samples are acquired at $5 \times$ magnification using a standard optical microscope (BX-60, Olympus) coupled to a charge coupled device (CCD) camera (VersArray, 1024B, Roper Scientific, Inc.) The enlarged image in Fig. 1b was constructed from eight image frames, each showing a portion of the sample, that were remapped using software written in Matlab (the Math Works, Inc.).

\section{Results and discussion}

\section{$X$-ray diffraction}

Figure 3 shows representative X-ray diffraction data for undrawn and drawn PLLA. The broad peak (lowest curve) corresponds to the undrawn PLLA which is semi- 


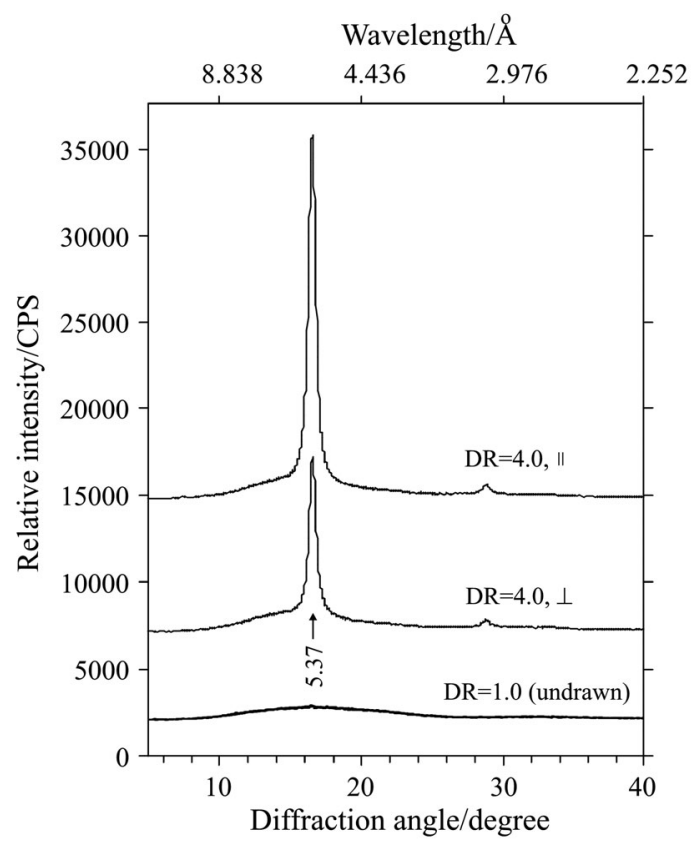

Fig. $3 \mathrm{X}$ ray diffraction data of PLLA. The broad XRD peaks for the undrawn sample are indicative of small crystallites in the starting material. At greater draw ratios, the PLLA is more crystalline and exhibits anisotropy consistent with molecular ordering along the draw axis

crystalline and exhibits a strongly amorphous character. This feature is present in the baseline region of the upper two plots, which correspond to a draw ratio of 4.0. The well defined peaks in these plots indicate the presence of a long-range order in the directions parallel and perpendicular to the draw axis. The larger of the two peaks (top curve) corresponds to diffraction arising from molecular order in the direction of the draw axis and demonstrates that the draw induced order is most prevalent along the draw direction. Although the degree of order in the direction perpendicular to the draw axis is significantly less, it is greater than in the amorphous material and corresponds to roughly the same Bragg spacing as the ordered periodicity along the draw direction. The crystallite size is smaller for the undrawn sample, $\sim 3 \mathrm{~nm}$, and much larger for the highly drawn sample (typically $>50 \mathrm{~nm}$ ) as calculated using the Scherrer equation:

$$
L=\frac{K \lambda}{\beta_{0} \cos \theta}
$$

where $L$ is the crystallite dimension, $\beta_{0}$ is the breadth of the reflection corrected for instrument response, $\lambda$ is the diffraction wavelength, $\theta$ is the diffraction angle, and $K$ is approximately unity [30]. 


\section{Scanning electron microscopy (SEM)}

The morphological changes of the drawn and undrawn PLLA were examined by SEM on drawn and amorphous PLLA samples without employing a sputter coat, Fig. 4. Localized charging effects were minimized by viewing a large area under low magnification and employing a relatively small beam voltage. Undrawn PLLA, Fig. 4a, appears to have a smooth surface in comparison with PLLA of draw ratio 4.0, which exhibits fibrils oriented in the direction of the draw axis, Fig. 4c. The sample of draw ratio 2.5, Fig. 4b, exhibits a largely unordered surface with some fibril formation. The SEM data suggests that as PLLA is cold-drawn, elongation occurs in localized areas separated by largely unordered regions. With continued drawing, an increase in the number of fibrillar formations is observed.
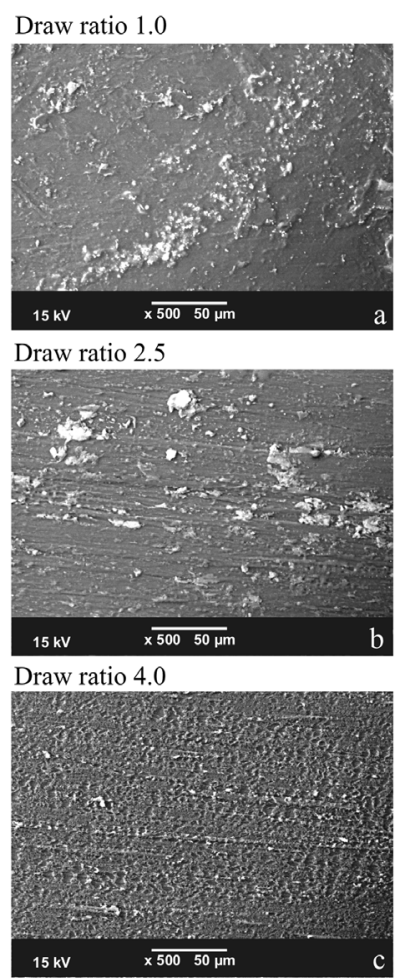

Fig. 4 SEM micrograph images for a undrawn PLLA (draw ratio of 1), b PLLA of draw ratio 2.5 and c PLLA of draw ratio 4.0. The samples are not sputter coated. Striations along the draw axis are present in the drawn PLLA and are most pronounced in the sample of draw ratio 4.0

\section{Differential scanning calorimetry}

Listed in Table 1 are DSC data for samples with draw ratios between 1.0 and 5.5. It is apparent that the crystallization enthalpies tend to decrease with increasing draw ratio. 
Table 1 Average DSC results for 4 sets of samples of draw ratios 1 to draw ratios 5.5

\begin{tabular}{lcrccccc}
\hline Draw ratio & $T_{\mathrm{g}} /{ }^{\circ} \mathrm{C}$ & $T_{\mathrm{c}} /{ }^{\circ} \mathrm{C}$ & $\Delta H_{\mathrm{c}} / \mathrm{J} \mathrm{g}^{-1}$ & $T_{\mathrm{c} 2} /{ }^{\circ} \mathrm{C}$ & $\Delta H_{\mathrm{c} 2} / \mathrm{J} \mathrm{g}^{-1}$ & $T_{\mathrm{m}} /{ }^{\circ} \mathrm{C}$ & $\Delta H_{\text {fus }} / \mathrm{J} \mathrm{g}^{-1}$ \\
\hline 1.0 & $50.2 \pm 5.0$ & 101.3 & 36.4 & 150.6 & 2.5 & $172.1 \pm 2.3$ & $49.6 \pm 3.2$ \\
1.5 & $49.9 \pm 5.1$ & 86.6 & 27.1 & 152.0 & 2.8 & $168.7 \pm 6.5$ & $51.7 \pm 2.6$ \\
2.0 & $50.8 \pm 6.6$ & 82.1 & 20.6 & 153.5 & 4.5 & $171.1 \pm 2.0$ & $52.2 \pm 4.7$ \\
2.5 & $50.2 \pm 4.1$ & 87.6 & 22.2 & 152.3 & 3.1 & $171.0 \pm 1.9$ & $49.8 \pm 4.3$ \\
3.0 & $48.3 \pm 5.5$ & 89.9 & 20.7 & 153.8 & 3.3 & $171.1 \pm 2.0$ & $53.4 \pm 4.7$ \\
3.5 & $49.1 \pm 4.9$ & 77.5 & 11.8 & 151.2 & 2.8 & $170.7 \pm 1.9$ & $53.5 \pm 1.2$ \\
4.0 & $47.7 \pm 5.2$ & 84.6 & 10.1 & 153.7 & 3.2 & $170.8 \pm 2.0$ & $54.3 \pm 2.2$ \\
4.5 & $50.2 \pm 6.2$ & 88.6 & 20.4 & 152.1 & 4.0 & $171.0 \pm 2.4$ & $55.6 \pm 2.5$ \\
5.0 & $49.6 \pm 7.9$ & & & & & $170.3 \pm 2.1$ & $56.3 \pm 2.3$ \\
5.5 & $49.8 \pm 6.0$ & & & & & $171.0 \pm 3.0$ & $51.7 \pm 5.2$ \\
\hline
\end{tabular}

As a PLLA sample is mechanically drawn, the molecular chains become more ordered which in turn increases the mechanical strength of the polymer. The enthalpy of crystallization $\left(\Delta H_{\mathrm{c}}\right)$ decreases from $36.4 \mathrm{~J} \mathrm{~g}{ }^{1}$ at a draw ratio of 1.0 to $10.1 \mathrm{~J} \mathrm{~g}{ }^{1}$ at a draw ratio 4.0. The presence of the glass transition and the crystallization exotherm reveal the presence of both amorphous and crystalline regions in the polymer. At draw ratios of 5.0 and higher, there is no crystallization exotherm present, which is an indication that the amorphous regions have become crystalline as a result of mechanical drawing of the polymer. A second exotherm is observed for all draw ratios, with the exception of draw ratios 5.0 and 5.5, near the melting temperature $\left(T_{\mathrm{m}}\right)$ due to additional crystallization during the experiment. This exotherm is obscured by the melting endotherm in conventional DSC and is best observed using modulated DSC. Since we are interested in investigating PLLA for use as an artificial cell scaffold material for use at temperatures near $37^{\circ} \mathrm{C}$, it is necessary to correct for both DSC crystallization enthalpies, which occur at temperatures higher than physiological temperatures, when calculating the percent crystallinity for the drawn PLLA [21]. The percent crystallinity, $\chi_{\mathrm{c} \text {, pre-DSC}}$, at physiologically relevant temperatures below the glass transition is calculated by subtracting $\Delta H_{\mathrm{c}}$ and $\Delta H_{\mathrm{c} 2}$ from the enthalpy of fusion $\left(\Delta H_{\mathrm{f}}\right)$ using the following equation:

$$
\chi_{\mathrm{c}, \mathrm{pre} D \mathrm{SSC}}=100\left(\frac{\Delta H_{\mathrm{f}}-\Delta H_{\mathrm{c}}-\Delta H_{\mathrm{c} 2}}{93.6}\right)
$$

where $93.6 \mathrm{~J} \mathrm{~g}{ }^{1}$ is the reported $\Delta H_{\mathrm{f}}$ for a sample that is $100 \%$ crystalline [31].

With the exception of the 2.5 draw ratio, the percent crystallinity increases with increasing draw ratio up to 5.0 (Fig. 5). At higher draw ratios, there is a slight decrease in the degree of sample crystallinity which is confirmed by the plot of $\chi_{c \text {, pre-DSC }}$ as a function of draw ratio.

Further examination of the sample reveals that the induced sample crystallinity is not uniform throughout the drawn neck region of the sample. The image in Fig. 1b shows a segment from a drawn PLLA dumbbell of draw ratio 2.5. While the appear- 


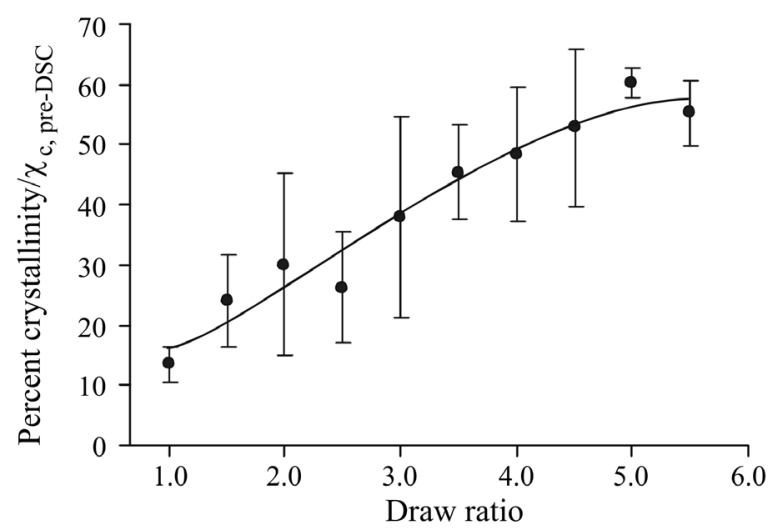

Fig. 5 The percent crystallinity of PLLA plotted as a function of draw ratio

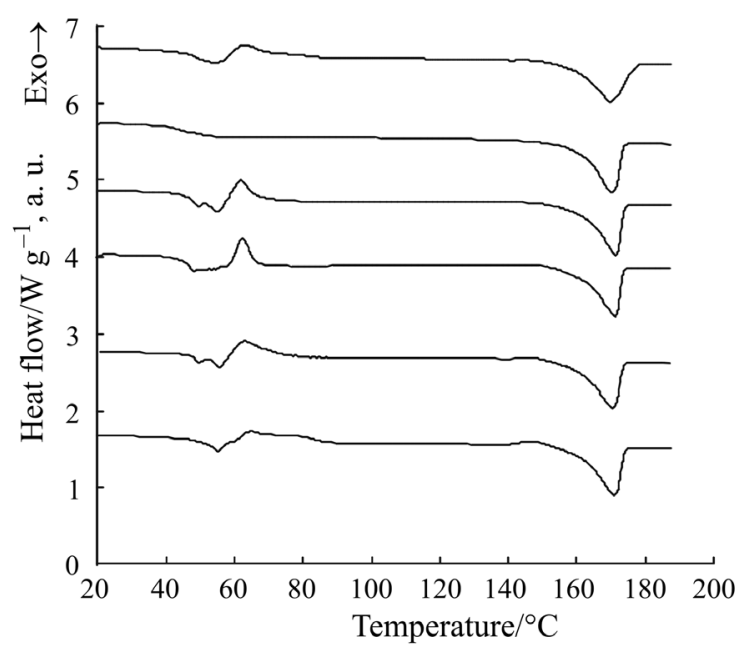

Fig. 6 DSC data for all segment 1 pieces (draw ratio 2.5) with a heating rate of $5^{\circ} \mathrm{C}$ in a nitrogen atmosphere

ance of striations parallel to the draw axis is indicative of long-range order, there are clear inhomogeneities as designated by the arrows. Table 2 gives the DSC data as well as the calculated percent crystallinities for all segments taken from the six samples at a draw ratio of 2.5. The change in heat capacities $\left(\Delta C_{\mathrm{p}}\right)$ decrease from segment 4 to segment 0 which indicates a decrease in the amorphous content of the polymer towards the central region of the dumbbell. The averaged crystallization enthalpies are highest for segment 4 (Table 2g). The curves shown in Fig. 6 represent all segment 4 pieces and reveal an endotherm at the glass transition that is likely due to the enthalpy stress-relaxation effect [15]. The calculated percent crystallinity varies considerably throughout the drawn dumbbell samples and there exists increasingly less crystalline character in segments $2-4$. While, the degree of crystallinity tends to in- 


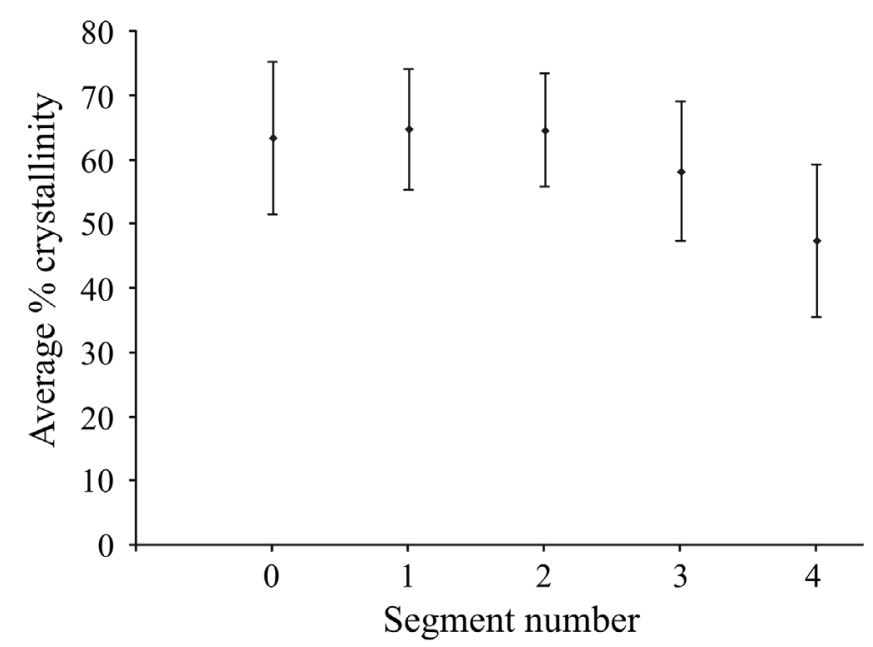

Fig. 7 Average percent crystallinity as a function of segment position along the draw axis for samples of draw ratio 2.5

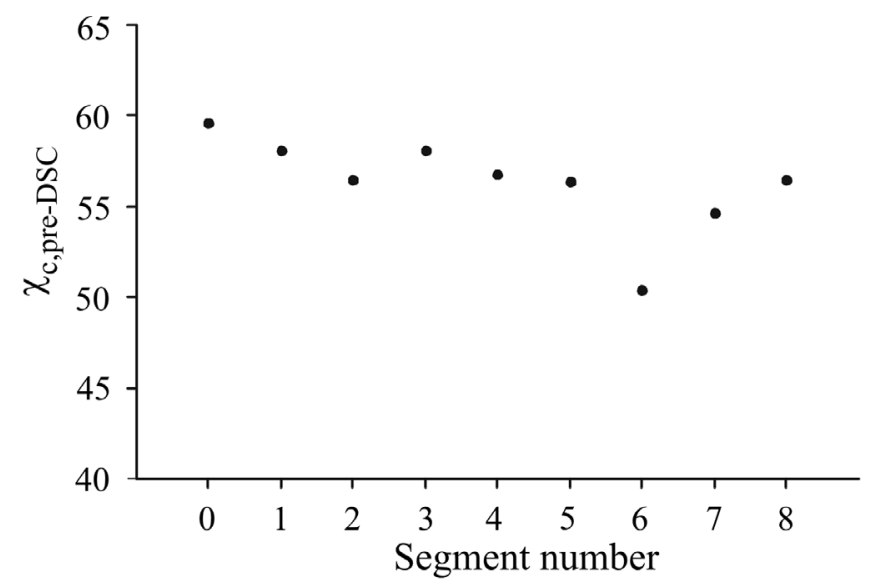

Fig. 8 Percent crystallinity as a function of segment position along the draw axis for a sample of draw ratio 4.0

crease toward the center of the dumbbell, the center segment cannot be assumed to be the most crystalline. For the samples studied here, the averaged results show that segment 1 exhibits the highest degree of crystallinity (Fig. 7). In addition, the widths of the error bars demonstrate that considerable variability exists between corresponding segments from different samples. We surmise that segment 1 is the most likely region in our samples where necking first occurred during the cold-drawing process. It is this segment that has the highest degree of crystallinity on average and, therefore, the most likelihood of draw induced ordering. In a similar manner, the percent crystallinity was calculated for all segments in the sample of draw ratio 4.0. There is less variability in 
Table 2a Conventional DSC for sample 1 of draw ratio $2.5^{*}$

\begin{tabular}{lccccccccc}
\hline Segment & $\begin{array}{c}T_{\mathrm{g}} / \\
{ }^{\circ} \mathrm{C}\end{array}$ & $\begin{array}{c}\Delta C_{\mathrm{p}} / \\
\mathrm{J} \mathrm{g}^{-1}{ }^{\circ} \mathrm{C}^{-1}\end{array}$ & $\begin{array}{c}T_{\mathrm{c}} \mathrm{C} \\
{ }^{\circ} \mathrm{C}\end{array}$ & $\begin{array}{c}\Delta H_{\mathrm{c}} / \\
\mathrm{J} \mathrm{g}^{-1}\end{array}$ & $\begin{array}{c}T_{\mathrm{c} 2} / \\
{ }^{\circ} \mathrm{C}\end{array}$ & $\begin{array}{c}\Delta H_{\mathrm{c} 2} / \\
\mathrm{J} \mathrm{g} \mathrm{g}^{-1}\end{array}$ & $\begin{array}{c}T_{\mathrm{m}} / \\
{ }^{\circ} \mathrm{C}\end{array}$ & $\begin{array}{c}\Delta H_{\mathrm{m}} / \\
\mathrm{J} \mathrm{g}^{-1}\end{array}$ & $\chi_{\mathrm{c}, \text { pre-DSC }}$ \\
\hline 4 & 53.5 & 1.6 & 64.5 & 27.4 & 147.3 & 4.5 & 170.9 & 65.1 & 35.5 \\
3 & 53.5 & 0.9 & 60.9 & 18.0 & & & 170.9 & 66.6 & 51.8 \\
2 & 55.2 & 0.5 & 60.3 & 18.2 & & & 171.1 & 69.0 & 54.3 \\
1 & 53.6 & 0.1 & 63.2 & 12.4 & & & 171.1 & 55.9 & 46.4 \\
0 & 56.3 & 0.2 & 63.2 & 12.0 & & & 171.1 & 53.9 & 44.9 \\
1 & 46.5 & 0.3 & 63.9 & 10.6 & & & 172.2 & 70.5 & 64.0 \\
2 & 41.5 & 0.2 & 63.0 & 6.3 & & & 170.3 & 69.0 & 67.0 \\
3 & 46.1 & 0.3 & 62.7 & 10.0 & & & 170.5 & 62.2 & 55.7 \\
4 & 40.8 & 0.2 & 62.2 & 12.0 & & & 170.5 & 69.4 & 60.9 \\
\hline
\end{tabular}

Table 2b Conventional DSC for sample 2 of draw ratio $2.5^{*}$

\begin{tabular}{lccccccccc}
\hline Segment & $\begin{array}{c}T_{\mathrm{g}} / \\
{ }^{\circ} \mathrm{C}\end{array}$ & $\begin{array}{c}\Delta C_{\mathrm{p}} / \\
\mathrm{J} \mathrm{g}^{-1}{ }^{\circ} \mathrm{C}^{-1}\end{array}$ & $\begin{array}{c}T_{\mathrm{c} /}{ }^{\circ} \mathrm{C} \\
4\end{array}$ & $\begin{array}{c}\Delta H_{\mathrm{c}} / \\
\mathrm{J} \mathrm{g}^{-1}\end{array}$ & $\begin{array}{c}T_{\mathrm{c} 2} / \\
{ }^{\circ} \mathrm{C}\end{array}$ & $\begin{array}{c}\Delta H_{\mathrm{c} 2} / \\
\mathrm{J} \mathrm{g}^{-1}\end{array}$ & $\begin{array}{c}T_{\mathrm{m}} / \\
{ }^{\circ} \mathrm{C}\end{array}$ & $\begin{array}{c}\Delta H_{\mathrm{m}} / \\
\mathrm{J} \mathrm{g}^{-1}\end{array}$ & $\chi_{\mathrm{c}, \text { pre-DSC }}$ \\
\hline 3 & 48.5 & 1.2 & 62.8 & 27.7 & 146.6 & 1.2 & 170.5 & 64.5 & 38.0 \\
2 & 49.1 & 1.0 & 60.7 & 24.7 & & & 171.3 & 67.0 & 45.2 \\
1 & 49.5 & 1.0 & 61.8 & 14.2 & & & 170.6 & 67.7 & 57.2 \\
0 & 50.2 & 0.9 & 62.6 & 11.3 & & & 170.4 & 69.2 & 61.8 \\
1 & 48.3 & 0.2 & 64.0 & 12.2 & & & 170.9 & 66.5 & 58.0 \\
2 & 49.6 & 0.8 & 63.0 & 11.1 & & & 170.1 & 69.6 & 62.5 \\
3 & 48.1 & 1.2 & 62.9 & 9.6 & & & 170.7 & 66.8 & 61.2 \\
4 & 49.2 & 1.1 & 60.9 & 20.3 & & & 170.2 & 69.3 & 52.3 \\
\hline
\end{tabular}

Table 2c Conventional DSC for sample 3 of draw ratio $2.5^{*}$

\begin{tabular}{lccccccccc}
\hline Segment & $\begin{array}{c}T_{\mathrm{g}} / \\
{ }^{\circ} \mathrm{C}\end{array}$ & $\begin{array}{c}\Delta C_{\mathrm{p}} / \\
\mathrm{J} \mathrm{g}^{-1}{ }^{\circ} \mathrm{C}^{-1}\end{array}$ & $\begin{array}{c}T_{\mathrm{c}} / \\
{ }^{\circ} \mathrm{C}\end{array}$ & $\begin{array}{c}\Delta H_{\mathrm{c}} / \\
\mathrm{J} \mathrm{g}^{-1}\end{array}$ & $\begin{array}{c}T_{\mathrm{c} 2} / \\
{ }^{\circ} \mathrm{C}\end{array}$ & $\begin{array}{c}\Delta H_{\mathrm{c} 2} / \\
\mathrm{J} \mathrm{g}^{-1}\end{array}$ & $\begin{array}{c}T_{\mathrm{m}} / \\
{ }^{\circ} \mathrm{C}\end{array}$ & $\begin{array}{c}\Delta H_{\mathrm{m}} / \\
\mathrm{J} \mathrm{g}^{-1}\end{array}$ & $\chi_{\mathrm{c}, \text { pre-DSC }}$ \\
\hline 4 & 46.6 & 0.7 & 62.2 & 24.1 & 148.2 & 0.8 & 171.3 & 64.2 & 42.0 \\
3 & 47.2 & 1.8 & 58.8 & 23.3 & & & 170.7 & 69.0 & 48.9 \\
1 & 46.9 & 1.0 & 56.3 & 13.1 & & & 170.0 & 69.2 & 60.0 \\
0 & 45.6 & 0.4 & 63.0 & 12.6 & & & 170.8 & 66.5 & 57.6 \\
1 & 46.0 & 0.2 & 63.5 & 9.0 & & & 170.5 & 67.1 & 62.0 \\
2 & 45.5 & 0.3 & & & & 171.6 & 68.8 & 73.5 \\
3 & 47.4 & 0.8 & & & & & 170.7 & 70.5 & 75.3 \\
4 & 49.2 & 0.7 & 61.9 & 10.8 & & & 170.6 & 70.9 & 64.2 \\
\hline
\end{tabular}


Table 2d Conventional DSC for sample 4 of draw ratio $2.5^{*}$

\begin{tabular}{lccccccccc}
\hline Segment & $\begin{array}{c}T_{\mathrm{g}} / \\
{ }^{\circ} \mathrm{C}\end{array}$ & $\begin{array}{c}\Delta C_{\mathrm{p}} / \\
\mathrm{J} \mathrm{g}^{-1}{ }^{\circ} \mathrm{C}^{-1}\end{array}$ & $\begin{array}{c}T_{\mathrm{c}} / \\
{ }^{\circ} \mathrm{C}\end{array}$ & $\begin{array}{c}\Delta H_{\mathrm{c}} / \\
\mathrm{J} \mathrm{g}^{-1}\end{array}$ & $\begin{array}{c}T_{\mathrm{c} 2} / \\
{ }^{\circ} \mathrm{C}\end{array}$ & $\begin{array}{c}\Delta H_{\mathrm{c} 2} / \\
\mathrm{J} \mathrm{g}^{-1}\end{array}$ & $\begin{array}{c}T_{\mathrm{m}} / \\
{ }^{\circ} \mathrm{C}\end{array}$ & $\begin{array}{c}\Delta H_{\mathrm{m}} / \\
\mathrm{J} \mathrm{g}^{-1}\end{array}$ & $\begin{array}{c}\chi_{\mathrm{c},} \\
\text { pre-DSC }\end{array}$ \\
\hline 4 & 48.0 & 1.0 & 61.9 & 23.1 & & & 171.4 & 68.0 & 48.0 \\
3 & 47.9 & 0.8 & 59.5 & 18.2 & & & 170.7 & 68.7 & 53.9 \\
2 & 48.5 & 1.0 & 59.7 & 15.5 & & & 170.4 & 67.0 & 55.1 \\
1 & 47.6 & 0.5 & 62.8 & 12.9 & & & 170.4 & 67.3 & 58.1 \\
0 & 44.9 & 0.2 & 63.1 & 10.7 & & & 170.6 & 69.7 & 63.0 \\
2 & 49.9 & 0.9 & 62.2 & 20.8 & & & 171.6 & 68.3 & 50.7 \\
3 & 49.2 & 1.0 & 61.2 & 22.4 & & & 171.4 & 69.1 & 49.9 \\
4 & 48.9 & 1.4 & 64.0 & 24.9 & 149.4 & 1.814 & 171.6 & 64.7 & 40.5 \\
& 48.8 & 1.1 & 65.2 & 26.7 & 147.7 & 3.756 & 171.6 & 66.3 & 38.3 \\
\hline
\end{tabular}

Table 2e Conventional DSC for sample 5 of draw ratio $2.5^{*}$

\begin{tabular}{lccccccccc}
\hline Segment & $\begin{array}{l}T_{\mathrm{g}} / \\
{ }^{\circ} \mathrm{C}\end{array}$ & $\begin{array}{c}\Delta C_{\mathrm{p}} / \\
\mathrm{J} \mathrm{g}^{-1}{ }^{\circ} \mathrm{C}^{-1}\end{array}$ & $\begin{array}{c}T_{\mathrm{c}} / \\
{ }^{\circ} \mathrm{C}\end{array}$ & $\begin{array}{c}\Delta H_{\mathrm{c}} / \\
\mathrm{Jg}^{-1}\end{array}$ & $\begin{array}{c}T_{\mathrm{c} 2} / \\
{ }^{\circ} \mathrm{C}\end{array}$ & $\begin{array}{c}\Delta H_{\mathrm{c} 2} / \\
\mathrm{J} \mathrm{g}^{-1}\end{array}$ & $\begin{array}{c}T_{\mathrm{m}} / \\
{ }^{\circ} \mathrm{C}\end{array}$ & $\begin{array}{c}\Delta H_{\mathrm{m}} / \\
\mathrm{J} \mathrm{g}^{-1}\end{array}$ & $\chi_{\mathrm{c}, \text { pre-DSC }}$ \\
\hline 4 & 41.6 & 1.4 & & & & & 170.6 & 69.6 & 74.3 \\
3 & 46.1 & 0.3 & 52.5 & 0.5 & & 170.2 & 65.9 & 69.9 \\
1 & 42.5 & 0.3 & 67.8 & 6.4 & & 169.7 & 68.6 & 66.4 \\
0 & 45.4 & 0.3 & & & 170.6 & 72.1 & 77.0 \\
1 & 47.5 & 0.3 & & & & 169.4 & 70.0 & 74.8 \\
2 & 44.2 & 0.3 & & & & 170.5 & 68.4 & 73.1 \\
3 & 45.3 & 0.3 & & & & 170.4 & 68.8 & 73.5 \\
4 & 42.5 & 0.8 & 72.3 & 1.0 & & 170.5 & 69.5 & 73.2 \\
\hline
\end{tabular}

Table 2f Conventional DSC for sample 6 of draw ratio $2.5^{*}$

\begin{tabular}{lccccccccc}
\hline Segment & $\begin{array}{c}T_{\mathrm{g}} / \\
{ }^{\circ} \mathrm{C}\end{array}$ & $\begin{array}{c}\Delta C_{\mathrm{p}} / \\
\mathrm{J} \mathrm{g}^{-1}{ }^{\circ} \mathrm{C}^{-1}\end{array}$ & $\begin{array}{c}T_{\mathrm{c}} / \\
{ }^{\circ} \mathrm{C}\end{array}$ & $\begin{array}{c}\Delta H_{\mathrm{c}} / \\
\mathrm{J} \mathrm{g}^{-1}\end{array}$ & $\begin{array}{c}T_{\mathrm{c} 2} / \\
{ }^{\circ} \mathrm{C}\end{array}$ & $\begin{array}{c}\Delta H_{\mathrm{c} 2} / \\
\mathrm{J} \mathrm{g} \mathrm{g}^{-1}\end{array}$ & $\begin{array}{c}T_{\mathrm{m}} / \\
{ }^{\circ} \mathrm{C}\end{array}$ & $\begin{array}{c}\Delta H_{\mathrm{m}} / \\
\mathrm{J} \mathrm{g}^{-1}\end{array}$ & $\chi_{\mathrm{c}, \text { pre-DSC }}$ \\
\hline 4 & 45.6 & 0.4 & 63.1 & 28.4 & & & 169.8 & 68.2 & 42.5 \\
3 & 43.9 & 0.6 & 63.3 & 4.5 & & 169.2 & 70.5 & 70.5 \\
1 & 49.6 & 0.2 & & & & 168.3 & 80.5 & 86.0 \\
0 & 42.6 & 0.1 & & & & & 170.3 & 69.8 & 74.5 \\
1 & 46.5 & 0.8 & & & & & 169.6 & 72.7 & 77.7 \\
2 & 44.0 & 0.4 & & & & & 169.3 & 72.0 & 76.9 \\
3 & 44.2 & 0.5 & 62.1 & 1.7 & & & 170.0 & 65.8 & 68.5 \\
4 & 43.6 & 0.2 & & & & & 169.4 & 67.2 & 71.8 \\
\hline
\end{tabular}


Table 2g Average DSC from samples of draw ratio $2.5^{*}$

\begin{tabular}{lccccccccc}
\hline Segment & $\begin{array}{c}T_{\mathrm{g}} / \\
{ }^{\circ} \mathrm{C}\end{array}$ & $\begin{array}{c}\Delta C_{\mathrm{p}} / \\
\mathrm{J} \mathrm{g}^{-1}{ }^{\circ} \mathrm{C}^{-1}\end{array}$ & $\begin{array}{c}T_{\mathrm{c}} / \\
{ }^{\circ} \mathrm{C}\end{array}$ & $\begin{array}{c}\Delta H_{\mathrm{c}} / \\
\mathrm{J} \mathrm{g} \mathrm{g}^{-1}\end{array}$ & $\begin{array}{c}T_{\mathrm{c} 2} / \\
{ }^{\circ} \mathrm{C}\end{array}$ & $\begin{array}{c}\Delta H_{\mathrm{c} 2} / \\
\mathrm{Jg} \mathrm{g}^{-1}\end{array}$ & $\begin{array}{c}T_{\mathrm{m}} / \\
{ }^{\circ} \mathrm{C}\end{array}$ & $\begin{array}{c}\Delta H_{\mathrm{m}} / \\
\mathrm{J} \mathrm{g} \mathrm{g}^{-1}\end{array}$ & $\chi_{\mathrm{c}, \text { pre-DSC }}$ \\
\hline 4 & 47.4 & 0.9 & 63.7 & 24.0 & 147.1 & 2.5 & 170.8 & 67.6 & 47.4 \\
3 & 47.3 & 0.8 & 61.6 & 14.2 & 149.4 & 1.8 & 170.5 & 67.6 & 58.2 \\
2 & 47.3 & 0.7 & 61.7 & 11.9 & & & 170.3 & 64.5 & 64.5 \\
1 & 47.1 & 0.4 & 63.0 & 13.1 & & & 170.7 & 68.2 & 64.7 \\
0 & 48.3 & 0.3 & 63.4 & 11.0 & & & 170.4 & 66.6 & 63.4 \\
\hline
\end{tabular}

${ }^{*}$ All data acquired at a heating rate of $5{ }^{\circ} \mathrm{C} \min { }^{1}$ in a nitrogen atmosphere.

the degree of crystallization with distance along the draw axis throughout the neck region, with segment 0 having the highest percent crystallinity as shown in Fig. 8.

Table 3 shows the results from modulated temperature DSC for segment 4 at a draw ratio of 2.5. The advantage of MTDSC is that non-reversible transitions such as crystallization can be separated and investigated independently from the reversible processes [21]. Figure 9 shows the corresponding curves for segment 4. Again, the non-reversible heat flow data reveals an exothermic transition indicative of crystallite formation that occurs during the melting process, yet no exotherm is observable after the glass transition in the total heat flow curve [32].

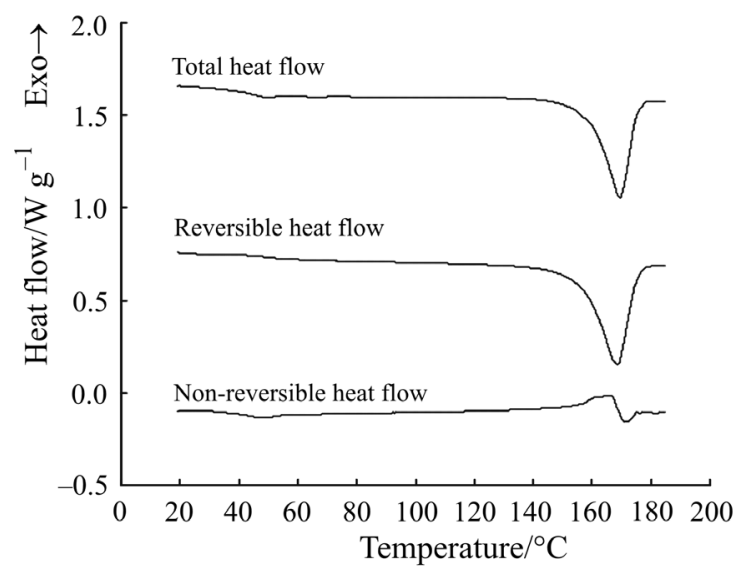

Fig. 9 Modulated DSC of drawn PLLA (draw ratio of 2.5, segment 4). The heating rate is $5^{\circ} \mathrm{C} \mathrm{min}-1$ in a nitrogen atmosphere. An exothermic transition consistent with crystal formation is revealed in the non reversible heat flow curve near the melting temperature endotherm

From the reversing and non-reversing heat flow data listed in Table 3, it appears that more than one crystallization process occurs during heating, which underscores the need to correct for both crystallization enthalpies when calculating percent crystallinity in PLLA from the DSC data. In addition, we observe a repeatable 


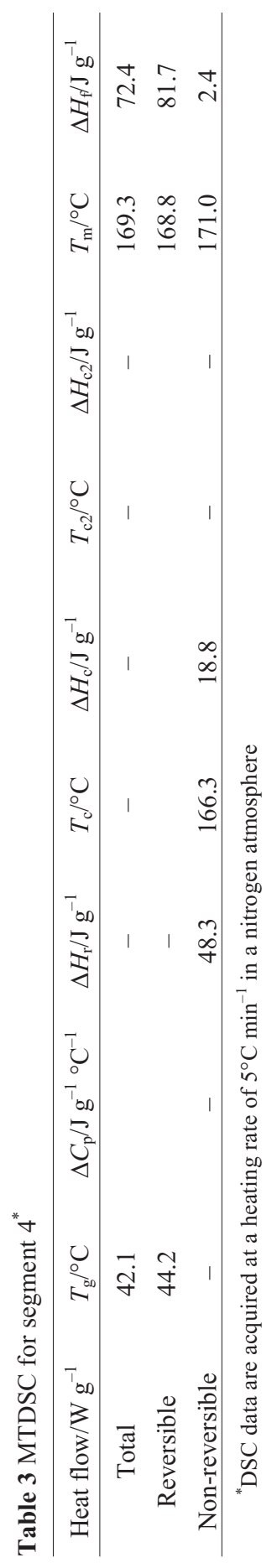


pre-exotherm in the raw modulated heat flow data relevant to the baseline before melting is achieved.

\section{Conclusions}

DSC is a useful tool for determining large-scale heterogeneities in cold-drawn PLLA. The overall DSC results reveal variable crystallinity throughout the drawn samples with the highest degree of crystallinity toward the center of the drawn region. This indicates that draw induced ordering is correlated to some degree with crystallinity, but it is not possible to make accurate quantitative estimates of the crystalline content directly from the draw ratio. Moreover, modulated DSC is better suited than conventional DSC to the investigation of PLLA crystallization at temperatures near the melting temperature because underlying crystallization processes that occur during the melt can be detected and accounted for in the final determination of percent crystallinity. For cold-drawn PLLA, the crystalline content increases on average with draw ratio, yet the maximum percent crystallinity is not explicitly dependent on draw ratio. While this investigation is a first step towards understanding the roles of orientation and crystallinity in PLLA scaffolds, our results indicate that piezoelectricity in PLLA as reported by Fukada et al. is long-range orientational-order dependent more than it is crystallinity dependent. While crystallinity and piezoelectricity are two phenomena closely related to each other through the manifestation of order, the osteogenic potential of each in PLLA should be considered independently.

The authors extend appreciation to undergraduate students Jennifer Collis, Jennifer Seegichetla and Patrick Odea, Department of Chemistry, Cleveland State University for their help with data acquisition. In addition, we thank Mark Sparrow of Borg Warner Transmission Systems, MI, for acquiring SEM images of our samples. Funding for this work was granted by the Society for Analytical Chemists of Pittsburgh and Cleveland State University.

\section{References}

1 H. Tsuji, Polymer, 43 (2002) 1789.

2 H. Tsuji, Biomaterials, 24 (2003) 537.

3 D. W. Grijpma, H. Altpeter, M. J. Bevis and J. Feijen, Polymer International, 51 (2002) 845.

4 S. Zhou, X. Deng, X. Li, W. Jia and L. Liu, J. Appl. Poly. Sci., 91 (2004) 1848.

5 A. S. P. Lin, T. H. Barrows, S. H. Cartmell and R. E. Guldberg, Biomaterials, 24 (2003) 481.

6 M. Borden, M. Attawia and C. T. Laurencin, J. Biomed. Mater. Res., 61 (2002) 421.

7 G. G. Giordano, T. C. Thomson, S. L. Ishaug, A. G. Mikos, S. Cumber, C. A. Garcia and

D. Lahiri Munir, J. Biomed. Mater. Res., 34 (1997) 87.

8 T. Hadlock, S. Singh, J. P. Vacanti and B. J. McLaughlin, Tissue Engineering, 5 (1999) 187.

9 H. Altpeter, M. J. Bevis, D. W. Grijpma and J. Feijen, J. Mat. Sci.: Materials in Medicine, 15 (2004) 175.

10 Y. S. Nam, J. J. Yoon and T. G. Park, J. Biomed. Mater. Res., 53 (2000) 1. 
11 T. Ouchi and Y. Ohya, J. Poly. Sci., 42 (2004) 453.

12 J. Y. Lim, S. H. Kim, S. Lim and Y. H. Kim, Macromol. Mater. Eng., 288 (2003) 50.

13 P. Mäkelä, T. Pohjonen, P. Törmälä, T. Waris and N. Ashammakhi, Biomaterials, 23 (2002) 2587.

14 H. Yu, N. Huang, C. Wang and Z. Tang, J. Appl. Poly. Sci., 88 (2003) 2557.

15 D. Cam, S. Hyon and Y. Ikada, Biomaterials, 16 (1995) 833.

16 L. K. Jong, K. H. Lee and B. S. Jin, Euro. Poly. J., 37 (2001) 907.

17 J. Lee, C. Ha and W. Lee, Mat. Sci. Eng. C, 24 (2004) 23.

18 H. Tsuji and A. D. Carpio, Biomacromolecules, 4 (2003) 7.

19 Y. Maeda, J. Therm. Anal. Cal., 70 (2002) 669.

20 F. W. Billmeyer, Jr., Textbook of Polymer Science, John Wiley and Sons, New York 1984, p. 280.

21 J. F. Turner II, A. Riga, A. O'Connor, J. Zhang and J. Collis, J. Therm. Anal. Cal., 75 (2004) 257.

22 A. I. Leonov, Int. J. Sol. Struct., 39 (2002) 5913.

23 E. Fukada, Biorheology, 32 (1995) 593.

24 T. Ochiai and E. Fukada, Jpn. J. Appl. Phys., 37 (1998) 3374.

25 Y. Ikada, Y. Shikinami, Y. Hara, M. Tagawa and E. Fukada, J. Biomed. Mat. Res., 30 (1996) 553.

26 E. Fukada, Jpn. J. Appl. Phys., 37 (1998) 2775.

27 W. Kuhn, Kolliodz Zeitschrift, 68 (1934) 2.

28 X. Yang and J. Sun, J. Polym. Sci. Part B: Polym. Phys., 40 (2002) 2646.

29 A. Riga and R. Collins, Encyclopedia of Analytical Chemistry, R.A. Meyers, John Wiley and Sons, Chichester, England 2000, p. 13147.

30 L. E. Alexander, X ray Diffraction Methods in Polymer Science, John Wiley and Sons, New York 1969, p. 335.

31 M. Yasuniwa, S. Tsubakihara, Y. Sugimoto and C. Nakafuku, J. Polym. Sci., 42 (2004) 25.

32 A. Gombás, P. Szabó Révész, M. Kata, G. Regdon Jr. and I. Erős, J. Therm. Anal. Cal., 68 (2002) 503. 